\title{
A population-level examination of the magnitude of relationship between physical activity and academic achievement
}

Mia Papasideris ( $\square$ mpapasid@edu.uwaterloo.ca )

University of Waterloo https://orcid.org/0000-0002-3440-4324

Scott Leatherdale

University of Waterloo

Kate Battista

University of Waterloo

Peter A. Hall

University of Waterloo

Research article

Keywords: Physical activity, Brain, Academic achievement, Youth, Adolescents

Posted Date: June 25th, 2019

DOI: https://doi.org/10.21203/rs.2.10654/v1

License: (9) This work is licensed under a Creative Commons Attribution 4.0 International License.

Read Full License 


\section{Abstract}

Background Although physical activity has traditionally been thought to compete with academic activities in terms of academic performance outcomes, more recent studies have suggested that the brain health benefits of exercise could in theory compensate for this. However, to date no adequately powered prospective studies have attempted to reconcile these two competing possibilities. The objective of this study is to determine the direction and magnitude of the association between physical activity and academic performance in a large prospective sample of adolescents. Methods Linear regression mixed models with random intercepts and multinomial ordinal generalized estimating equations were employed to analyze the relationship between measures of physical activity and academic performance from the COMPASS study ( $N=9,898$ linked participant data cases from year 2 (2013-2014) to year 4 (2015-2016)). Results The linear relationships between minutes of moderate to vigorous physical activity and academic performance (English: $r=-.047, p<.000$; Math: $r=-.026, p=0.008$ ) as well as meeting the national physical activity guidelines and academics performance (English: est $=-0.052, p=.004$; Math: est $=-0.052, p=.028$ ) were negative and trivial in magnitude. Organized sport participation showed slight positive associations with academic performance, but these were also of trivial magnitude. Conclusions Physical activity does not predict academic achievement prospectively in this population sample; findings suggest no net cost or clear benefit in relation to academic performance. Advocacy for physical activity programming for adolescent populations may best be undertaken with reference to lack of net academic performance cost, rather than presence of benefit.

\section{Background}

Regular physical activity has physical and mental health benefits, including enhanced cardiorespiratory fitness, a decreased risk of type 2 diabetes, reduced mortality, as well as improved mood and reduced depressive symptoms [1-5]. Exercise regimes also improve the functional and cognitive capacity of older adults $[6,7]$. The latter effects appear especially salient for brain regions supporting cognitive control and memory [7-11]. These "brain benefits" of exercise may be present throughout the lifespan and may be especially important for adolescents whom rely on such functions in the academic sphere [10,12-14]. Despite the evidence supporting the association between exercise and enhanced brain function, it is not clear to what extent such enhancements translate into improved academic performance.

In contrast, the removal of physical activity from school curriculums decades ago across North America was often rationalized based on an assumption that physical activity programming competes for time with academic subjects. Effectively, this perspective posited a negative effect of physical activity on academic performance based on time competition between the two. The "brain-benefit" and "timecompetition" hypotheses pertaining to physical activity and academic performance both posit a significant relationship, but in opposite directions. Understanding the nature of this relationship is therefore important to inform future physical activity programming for adolescents. 
Systematic and meta-analytic reviews of the literature have shown variable results ranging from null to small positive effects of physical activity interventions (both acute and long-term) on academic performance [15-20]. However, among the studies reviewed there is a high degree of variability in the quality of the study designs, a limited number of studies with sufficient power, as well as a large degree of heterogeneity in the intervention components and academic outcomes assessed [16-18]. More problematic is the inability to achieve blinding (single or double) in such trials. For these reasons, longitudinal study designs may have something important to add to the evidence base, particularly when they are relatively large in size.

The results of previous longitudinal analyses examining the relationship between physical activity and academic achievement in adolescence have also been variable. Several studies have found small to moderate associations [21-24], and some have found null associations,[25] although the sample sizes have been limited in some cases and the absolute effect sizes have been relatively small.

The current study endeavours to address the limitations present the literature through the use a large prospective population-based dataset to evaluate the "time-competition" and "brain-benefit" hypotheses, as well as the possibility of a null effect. We examine the association separately for two indicators of academic performance (English and Math grades) and three different parameters of physical activity (minutes of moderate-to-vigorous physical activity, percent achieving national activity guidelines, and organized sport participation). The secondary aim of this investigation is to discover the direction of this relationship, if a significant association is present. In keeping with prior smaller scale studies, we hypothesized that the prospective association between physical activity and academic performance would be positive in direction and small-to-moderate in magnitude. The large sample size and longitudinal nature of COMPASS study provides statistical power and a more definitive representation of the direction and magnitude of association than possible in any prior study.

\section{Methods}

\section{Design:}

The COMPASS study is an ongoing prospective cohort study (2012-2021) that collects annual hierarchical longitudinal data from a convenience sample of secondary schools in Ontario and Alberta, Canada (grades 9-12). A total of 89 schools were sampled, 79 in Ontario and 10 in Alberta. The study examines the impact of school policies and programs on a variety of student health behaviours, including physical activity, health eating, substance use and mental health, as well as academic achievement. Details of the COMPASS study, including sampling and data collection are available online (www.compass.uwaterloo.ca). The COMPASS study was approved by the Human Research Ethics Board at the University of Waterloo. This study uses data from years 2 (2013-14) and 4 (2015-16) of the COMPASS study. 


\section{Participants:}

In year 2 (2013-2014) and year 4 (2015-2016) of the COMPASS study, participants were recruited using active-information passive-consent permission protocols. The parents or guardians were mailed an information letter and then were asked to either call or email the COMPASS recruitment leader in the event that they did not want their child to participate, and students could refuse to participate at any time. In year 2, 45,298 students (participation rate 80.2\%), while in year 4, 40,436 students (participation rate $79.9 \%)$ participated. The majority of missing respondents were from absenteeism or scheduled spares at the time of the data collection.

Students were linked anonymously over time using a self-generated identification code. Details of the data linkage process are described elsewhere [26]. This study examined a longitudinal sample of 11,220 students who were successfully linked across years 2 and 4 of the study. Among this group, students with missing data on any of the measures included in the analysis were excluded, resulting in a final longitudinal sample of 9,898 students.

\section{Data Collection Tool:}

The COMPASS student questionnaire $\left(\mathrm{C}_{\mathrm{q}}\right)$, is an anonymous, self-administered questionnaire and was used to collect student level data on a number of health-related outcomes such as obesity, sedentary behaviour and substance use, as well as correlates on behaviours and demographic attributes [27]. $C_{q}$ data was collected as large whole-school samples during class time and was therefore designed to be completed in one 30 to 40 -minute class period [27]. Survey items were chosen in order to meet both science- based and practice-based concerns.

\section{Measures:}

\section{Physical Activity Measures}

Students completed two questions on the $\mathrm{C}_{\mathrm{q}}$ regarding their daily number of minutes of both vigorous and moderate physical activity. Vigorous physical activity was defined as activities such as "jogging, team sports, fast dancing, and any other physical activities that increase your heart rate and make you breathe hard and sweat." Moderate physical activity was defined as "lower intensity activities such as walking, biking to school, and recreational swimming." Based on responses to these questions, a continuous measure of average daily moderate to vigorous physical activity (MVPA) was calculated. Additionally, a binary measure of whether students met the minimum Canadian physical activity guidelines of at least 60 minutes of MVPA per day was utilized. The measures were found to have high test-retest reliability and were significantly correlated with accelerometer-measured behaviours [27]. While 
the correlation between self-report and accelerometer measures were low to modest, the results are comparable to most other studies using accelerometers to validate self-report physical activity [27].

Students were also asked about their participation in intramural, varsity and league sports. To determine intramural sports participation students were asked "Do you participate in before-school, noon hour, or after-school physical activities organized by your school?" To determine varsity sports participation students were asked "Do you participate in competitive school sports teams that compete against other schools?" To determine league sports participation, students were asked "Do you participate in league or team sports outside of school?"

\section{Academic Achievement Measures}

To measure academic achievement, students were asked questions about their most recent math and English grades with the questions "In your current or most recent Math course, what is your approximate overall mark?" and "In your current or most recent English course, what is your approximate overall mark?" Response options ranged from "Less than 50\%" to "90\% - 100\%." Grade categories were treated as continuous variables ranging from 1 to 6 , with 1 indicating "Less than $50 \%$ " to 6 indicating " $90 \%-100 \%$."

\section{Control Variables}

Students were also asked demographic information on grade, sex, ethnicity and weekly spending money (as a proxy for socioeconomic status). To assess ethnicity, students were asked "How would you describe yourself," and could select any number of response options of "White", "Black", "Asian", "Aboriginal (First Nations, Metis, Inuit)", "Latin American/Hispanic" and "Other". Due to sample sizes, response options were collapsed to "White", "Asian", "Other" and "Mixed". To assess socioeconomic status, students were asked "About how much money do you usually get each week to spend on yourself or save?" Response options ranged from "Zero" to "More than \$100", as well as "I don't know".

Additional control variables included students' perceived importance of grades, time spent sleeping, and time spent doing homework. To measure perceived importance of grades, students were asked their agreement with the statement "Getting good grades is important to me". Response options were collapsed into "Strongly agree", "Agree" and "Disagree/Strongly Disagree". Time spent sleeping and doing homework were measured in minutes per day based on answers to the question "How much time per day do you usually spend doing the following activities?"

Statistical Analysis: 
Descriptive statistics were calculated for all variables in the analysis at baseline (year 2), as well as academic achievement variables at follow-up (year 4). Effect sizes were calculated for the relationship between baseline physical activity and grade at follow-up using correlations and Cohen's $f$ as effect size estimates (for raw and covariate-adjusted effects, respectively).

Sequential linear regression mixed models with random intercept, and multinomial ordinal generalized estimating equations (GEE) models were used to examine the association between baseline physical activity and sports participation on both academic outcomes at follow-up. All models controlled for baseline school grade, sex, ethnicity, weekly spending money, perceived importance of grades, time spent sleeping and time spent doing homework, as well as corresponding baseline Math/English grade. Models also accounted for school-level clustering, with the assumption that students from the same school will be more alike than students from different schools. However, equivalent non-clustered models were used to calculate Cohen's $f$ effect sizes. All analyses were conducted using the statistical software SAS 9.4. The procedure PROC MIXED was used for linear models and PROC GENMOD was used for the logistic GEE model. Statistical significance was set a $p<0.05$ for all analyses.

\section{Results}

Baseline descriptive information, including the demographic, academic and physical activity characteristics of the longitudinal sample $(N=9,898)$ can be found in Table 1 . At year $2,52 \%$ of the participants met the national physical activity guidelines (60 minutes/day), and $53 \%$ of participants met the guidelines at year 4 . In addition, students completed a mean 122.11 minutes $( \pm 81.31)$ average daily MVPA at baseline, and a mean 114.35 minutes $( \pm 84.53)$ at follow-up. In terms of academic achievement, the majority of students received Math and English grades in the $80-89 \%$ range (33\% and $40 \%$ respectively) at baseline. This was consistent with the majority at year 4 follow-up (Math $29 \%$ and English 42\%).

Zero-order Pearson correlation coefficients linking baseline average daily MVPA with subsequent academics were statistically significant, but negative in direction and trivial in absolute magnitude (English: $r=-.047, p<.000$; Math: $r=-.026, p=.009$ ). This association is consistent with the covariateadjusted linear regression models, which revealed a significant negative but trivial magnitude association between average daily MVPA at baseline and both academic outcomes at follow-up (Table 2\&3; English: est $=-.000, p=.029$; Math: est $=-.000, p=.019)$. The Cohen's $f$ effect size for this relationship was also negative but trivial in magnitude (Table 4; English: $f=-.022$; Math: $f=-.022$ ). Figure 1 provides a graphical representation of the Cohen's $f$ effect sizes for all relationships between physical activity predictors and both English and Math achievement.

Similar to average daily MVPA, the likelihood of better academic performance was lower as a function of meeting the national physical activity guidelines (English: est $=-0.052, p=.004$; Math: est $=-0.052, p=.028$ ) in covariate-adjusted models; again however, the effect was trivial in absolute magnitude (English: $f=-$ .030; Math: $f=-.022)$. 
Organized sport participation was significantly associated with higher grades in Math and English, but the magnitude of these associations approached zero (Table 4; Figure 1). Overall, effect sizes for activity predictors academic outcomes were only about $30 \%$ or less of the threshold for a "small" effect $(f=.14)$ by Cohen's interpretive conventions.

Categorical analysis of baseline physical activity variables and both academic outcomes using multinomial ordinal GEE models are presented in Table 5. In general, the results were consistent with the continuous analysis.

\section{Discussion}

The present investigation examined the magnitude and direction of the relationship between three indicators of physical activity (minutes of MVPA, percent achieving national physical activity guidelines, and organized sports participation) and two indicators of academic achievement (English and Math grades) in adolescents. Both continuous and categorical analyses of the variables found near-zero magnitude associations between physical activity at baseline and academic performance outcomes at follow-up. Similarly, meeting the national physical activity guidelines at baseline had no substantive benefit in relation to academic achievement at follow-up. In short, there was little support for a hypothesized net benefit of physical activity on academic performance.

Conversely, no evidence of adverse impact of physical activity was observed, indicating that higher levels of physical activity may have no effect overall on improving academic achievement at follow-up. The current study effectively suggests that the fears regarding the time competition between physical activity and academics may be, on the whole, not well founded. These results gain credibility when the sizable nature of this study is considered, as this was the single largest study to date that examined this potential association and the only population survey of this nature. All parameter estimates were highly precise (i.e., narrow confidence intervals) and generalizable to the larger population from which the sample was drawn.

This study has found little evidence of benefit from MVPA or from meeting the national physical activity guidelines on either indicator of academic achievement. Previous literature has hypothesized a positive relationship between the two variables as it is thought that the brain health benefits observed from exercise could be contributing to an increase in academic performance, as regions associated with the observed "brain benefits" of exercise are also important for academic attainment $[9,10,12,13,15]$.

A reliable but trivial benefit of varsity sport participation was observed in relation to academic performance, but this may or may not be of practical importance. Any such benefit could be driven solely by minimum academic requirements for participation in varsity athletics, for example. However, it is also the case that the more complex social environment offered by sport participation (compared to unstructured physical activity alone) could benefit brain development [28]. In addition, the social benefits, such as the formation of formal or informal academic assistance on school-based teams that do not work through the brain could potentially lead to slightly enhanced academic performance that has 
nothing to do with the brain per se. Finally, it is also possible that adolescents could experience other mental, social or physical health challenges that adversely impact both academic and sport participation, producing a similar pattern to what has been observed in this study.

Finally, the current findings provide a good example of the disjunction between effect size and statistical significance in large samples. Here we have documented trivial magnitude effects that are highly statistically significant simply because of the large sample size. Given the very narrow confidence intervals around our estimates of association, we can be quite confident in the precision of our estimates of the relationship magnitude between physical activity and academic achievement. This is an instance where the effect magnitude and confidence intervals are the focus of discussion rather than $p$-value [29].

The strengths of the current investigation include the use of a large longitudinal sample and high external validity. In addition, the COMPASS survey is a reliable and valid measure concordant with national surveillance tools and public health guidelines, which also lends to the credibility of the findings [27]. Weaknesses include the use of self-reported physical activity and academic achievement measures, both of which may be subject to social desirability bias. The use of self-reported measures also contributed missing data, which limited the available sample size for this study to a certain extent. Such influences may have impacted the magnitude and significance of the relationships examined. Future studies should include the use of accelerometers as a more objective measure of physical activity, and record the actual grades received in English and Math as opposed to collecting academic performance as a self-reported measure. It would also be beneficial to examine the longer-term exercise and academic trends over the lifespan to provide an even more accurate measure of the effect.

\section{Conclusions}

While a near-zero effect of physical activity on academic performance was observed, the design and large sample size of this study provides a more accurate estimation of this effect than any previous study to date. Therefore, this study contributes to current literature surrounding the potential academic impact of physical activity, as it is lacking in studies of this size and power.

While the current findings are not consistent with an assumption of strong academic benefits of physical activity, the results do not provide clear support for the "brain benefit." On the other hand, the lack of nontrivial negative relationship fails to support the "time cost" hypotheses. It is possible that both are actually correct and that they are mutually opposing forces resulting in a near-null overall association over time, but we can say that the net effect of such opposing factors may be a near zero association. Future studies should examine the possibility of mutual offsetting of time cost and brain benefit in relation to physical activity in the academic context.

From a policy perspective, these findings in suggest that advocacy for inclusion of physical activity programming and participation among adolescents should be based on the lack of net adverse impact on academics (i.e., time cost) and not specifically on expectation of net academic benefit. As physical activity has been shown to have other positive effects on both physical and mental health, 
public health initiatives or policies promoting physical activity in adolescents can do so without fear of adversely impacting academic achievement.

\section{Abbreviations}

MVPA: Moderate and vigorous physical activity

\section{Declarations}

Ethics Approval and Consent to Participate: The University of Waterloo Office of Research Ethics reviewed and approved all aspects of the study protocol (ORE \# 17264). All school boards and schools approved study procedures. Active-information passive-consent was gained from parents, and assent was obtained from included participants on data collection date. Parents or students could decline to participate at any time.

Consent for Publication: Not applicable.

Availability of Data and Materials: The data that support the findings of this study are available from the COMPASS study but restrictions apply to the availability of these data, which were used under license for the current study, and so are not publicly available.

Competing interests: None declared.

Funding: The COMPASS study has been supported by a bridge grant from the CIHR Institute of Nutrition, Metabolism and Diabetes (INMD) through the "Obesity - Interventions to Prevent or Treat" priority funding awards (OOP-110788; awarded to SL), an operating grant from the CIHR Institute of Population and Public Health (IPPH) (MOP-114875; awarded to SL), a CIHR project grant (PJT-148562; awarded to SL), a CIHR bridge grant (PJT-149092; awarded to KP/SL), a CIHR project grant (PJT-159693; awarded to KP), and by a research funding arrangement with Health Canada (\#1617-HQ-000012; contract awarded to $\mathrm{SL})$.

Authors' Contributions: MP led the writing process. SL conceived and supervised the study. KB completed the analysis. PAH conceived the analysis, supervised and led the writing process.

Acknowledgements: Not applicable.

\section{References}

1. Bailey AP, Hetrick SE, Rosenbaum S, Purcell R, Parker AG. Treating depression with physical activity in adolescents and young adults: a systematic review and meta-analysis of randomised controlled trials. Psychol Med. 2018;48:1068-83.

2. Gordon BR, McDowell CP, Lyons M, Herring MP. The Effects of Resistance Exercise Training on Anxiety: A Meta-Analysis and Meta-Regression Analysis of Randomized Controlled Trials. Sports 
Med. 2017;47:2521-32.

3. Janssen I, LeBlanc AG. Systematic review of the health benefits of physical activity and fitness in school-aged children and youth. Int J Behav Nutr Phys Act. 2010;7.

4. Zahl T, Steinsbekk S, Wichstrøm L. Physical Activity, Sedentary Behavior, and Symptoms of Major Depression in Middle Childhood. Pediatrics. 2017;139:e20161711.

5. Lear SA, Hu W, Rangarajan S, Gasevic D, Leong D, lqbal R, et al. The effect of physical activity on mortality and cardiovascular disease in 130000 people from 17 high-income, middle-income, and low-income countries: the PURE study. The Lancet. 2017;390:2643-54.

6. Groot C, Hooghiemstra AM, Raijmakers PGHM, van Berckel BNM, Scheltens P, Scherder EJA, et al. The effect of physical activity on cognitive function in patients with dementia: A meta-analysis of randomized control trials. Ageing Res Rev. 2016;25:13-23.

7. Kramer AF, Colcombe S. Fitness Effects on the Cognitive Function of Older Adults: A Meta-Analytic Study-Revisited. Perspect Psychol Sci. 2018;13:213-7.

8. Davis CL, Tomporowski PD, McDowell JE, Austin BP, Miller PH, Yanasak NE, et al. Exercise improves executive function and achievement and alters brain activation in overweight children: A randomized, controlled trial. Health Psychol. 2011;30:91-8.

9. Erickson KI, Voss MW, Prakash RS, Basak C, Szabo A, Chaddock L, et al. Exercise training increases size of hippocampus and improves memory. PNAS. 2011;108:6.

10. Hillman $\mathrm{CH}$, Erickson $\mathrm{KI}$, Kramer AF. Be smart, exercise your heart: exercise effects on brain and cognition. Nat Rev Neurosci. 2008;9:58-65.

11. Kramer AF, Erickson KI. Capitalizing on cortical plasticity: influence of physical activity on cognition and brain function. Trends Cogn Sci. 2007;11:342-8.

12. Åberg MAl, Pedersen NL, Cooper-Kuhn CM, Åberg ND, Nilsson M, Kuhn HG. Cardiovascular fitness is associated with cognition in young adulthood. PNAS. 2009;106:20906-20911.

13. Hillman CH, Pontifex MB, Castelli DM, Khan NA, Raine LB, Scudder MR, et al. Effects of the FITKids Randomized Controlled Trial on Executive Control and Brain Function. PEDIATRICS. 2014;134:e1063-71.

14. Westfall DR, Gejl AK, Tarp J, Wedderkopp N, Kramer AF, Hillman CH, et al. Associations Between Aerobic Fitness and Cognitive Control in Adolescents. Front Psychol. 2018;9:1298.

15. Singh AS, Saliasi E, van den Berg V, Uijtdewilligen L, de Groot RHM, Jolles J, et al. Effects of physical activity interventions on cognitive and academic performance in children and adolescents: a novel combination of a systematic review and recommendations from an expert panel. $\mathrm{Br} \mathrm{J}$ Sports Med. 2018;0:1-10.

16. Álvarez-Bueno C, Pesce C, Cavero-Redondo I, Sánchez-López M, Garrido-Miguel M, Martínez-Vizcaíno V. Academic Achievement and Physical Activity: A Meta-analysis. Pediatrics. 2017;140:e20171498.

17. Donnelly JE, Hillman CH, Castelli D, Etnier JL, Lee S, Tomporowski P, et al. Physical Activity, Fitness, Cognitive Function, and Academic Achievement in Children: A Systematic Review. Med Sci Sports 
Exerc. 2016;48:1197-222.

18. Watson A, Timperio A, Brown H, Best K, Hesketh KD. Effect of classroom-based physical activity interventions on academic and physical activity outcomes: a systematic review and meta-analysis. Int J Behav Nutr Phys Act. 2017;14:114.

19. Smith PJ, Blumenthal JA, Hoffman BM, Cooper H, Strauman TA, Welsh-Bohmer K, et al. Aerobic Exercise and Neurocognitive Performance: A Meta-Analytic Review of Randomized Controlled Trials: Psychosom Med. 2010;72:239-52.

20. Verburgh L, Königs M, Scherder EJA, Oosterlaan J. Physical exercise and executive functions in preadolescent children, adolescents and young adults: a meta-analysis. $\mathrm{Br} \mathrm{J}$ Sports Med. 2014;48:973-9.

21. Carlson SA, Fulton JE, Lee SM, Maynard LM, Brown DR, Kohl HW, et al. Physical Education and Academic Achievement in Elementary School: Data From the Early Childhood Longitudinal Study. Am J Public Health. 2008;98:721-7.

22. Kari J, Pehkonen J, Hutri-Kahonen N, Raitakari O, Tammelin T. Longitudinal Associations between Physical Activity and Educational Outcomes. Med Sci Sports Exerc. 2017;49:2158-66.

23. Lima RA, Pfeiffer KA, Møller NC, Andersen LB, Bugge A. Physical Activity and Sedentary Time Are Positively Associated With Academic Performance: A 3-Year Longitudinal Study. J Phys Act Health. 2019;16:177-83.

24. Wittberg RA, Northrup KL, Cottrell LA. Children's Aerobic Fitness and Academic Achievement: A Longitudinal Examination of Students During Their Fifth and Seventh Grade Years. Am J Public Health. 2012;102:2303-7.

25. Hansen DM, Herrmann SD, Lambourne K, Lee J, Donnelly JE. Linear/Nonlinear Relations of Activity and Fitness with Children's Academic Achievement. Med Sci Sports Exerc. 2014;46:2279-85.

26. Qian W, Battista K, Bredin C, et al. Assessing longitudinal data linkage results in the COMPASS study, COMPASS Technical Report Series. Waterloo: University of Waterloo; 2015.

https://uwaterloo.ca/compass-system/sites/ca.compass-

system/files/uploads/files/compass_report_-_assessing_longitudinal_data_linkage_results__volume_3_issue_4.pdf.

27. Leatherdale S, Laxer R, Faulkner G. Reliability and validity of the physical activity and sedentary behaviour measures in the COMPASS study. Waterloo: University of Waterloo; 2014. https://uwaterloo.ca/compass-system/sites/ca.compasssystem/files/uploads/files/compass_report___pa_validation_-_volume_2_issue_1.pdf.

28. Eime RM, Young JA, Harvey JT, Charity MJ, Payne WR. A systematic review of the psychological and social benefits of participation in sport for adults: informing development of a conceptual model of health through sport. Int J Behav Nutr Phys Act. 2013;10:135.

29. Amrhein V, Greenland S, McShane B. Scientists rise up against statistical significance. Nature. 2019;567:305. 


\section{Tables}

Table 1- Descriptive Characteristics of 9898 Linked Students from the COMPASS Study: Ontario and Alberta, 2013-2014/2015-2016 


\begin{tabular}{|c|c|c|c|}
\hline Variable & Levels & $\mathrm{n}$ & $\%$ \\
\hline \multirow[t]{4}{*}{ Grade } & 9 & 5110 & $52 \%$ \\
\hline & 10 & 4466 & $45 \%$ \\
\hline & 11 & 320 & $3 \%$ \\
\hline & 12 & 2 & $0 \%$ \\
\hline \multirow[t]{2}{*}{ Sex } & Female & 5226 & $53 \%$ \\
\hline & Male & 4672 & $47 \%$ \\
\hline \multirow[t]{4}{*}{ Ethnicity } & White & 7690 & $78 \%$ \\
\hline & Asian & 520 & $5 \%$ \\
\hline & Other & 992 & $10 \%$ \\
\hline & Mixed & 696 & $7 \%$ \\
\hline \multirow[t]{8}{*}{ Spending Money } & Zero & 1998 & $20 \%$ \\
\hline & $\$ 1$ to $\$ 5$ & 914 & $9 \%$ \\
\hline & $\$ 6$ to $\$ 10$ & 1117 & $11 \%$ \\
\hline & $\$ 11$ to $\$ 20$ & 1773 & $18 \%$ \\
\hline & $\$ 21$ to $\$ 40$ & 1220 & $12 \%$ \\
\hline & $\$ 41$ to $\$ 100$ & 981 & $10 \%$ \\
\hline & More than $\$ 100$ & 597 & $6 \%$ \\
\hline & I don't know & 1298 & $13 \%$ \\
\hline \multirow[t]{3}{*}{ Importance of Grades } & Strongly Agree & 6003 & $61 \%$ \\
\hline & Agree & 3568 & $36 \%$ \\
\hline & Disagree/Strongly Disagree & 327 & $3 \%$ \\
\hline \multirow[t]{2}{*}{ Intramural Sports Participation } & No & 5908 & $60 \%$ \\
\hline & Yes & 3990 & $40 \%$ \\
\hline \multirow[t]{2}{*}{ Varsity Sports Participation } & No & 5456 & $55 \%$ \\
\hline & Yes & 4442 & $45 \%$ \\
\hline \multirow[t]{2}{*}{ League Sports Participation } & No & 4160 & $42 \%$ \\
\hline & Yes & 5738 & $58 \%$ \\
\hline English Grade & Less than $50 \%$ & 67 & $1 \%$ \\
\hline
\end{tabular}




\begin{tabular}{|c|c|c|c|}
\hline & $50 \%-59 \%$ & 334 & $3 \%$ \\
\hline & $60 \%-69 \%$ & 1022 & $10 \%$ \\
\hline & $70 \%-79 \%$ & 3082 & $31 \%$ \\
\hline & $80 \%-89 \%$ & 4005 & $40 \%$ \\
\hline & $90 \%-100 \%$ & 1388 & $14 \%$ \\
\hline Math Grade & Less than $50 \%$ & 184 & $2 \%$ \\
\hline & $50 \%-59 \%$ & 680 & $7 \%$ \\
\hline & $60 \%-69 \%$ & 1206 & $12 \%$ \\
\hline & $70 \%-79 \%$ & 2380 & $24 \%$ \\
\hline & $80 \%-89 \%$ & 3256 & $33 \%$ \\
\hline & $90 \%-100 \%$ & 2192 & $22 \%$ \\
\hline Meets PA Guidelines & No & 4779 & $48 \%$ \\
\hline & Yes & 5119 & $52 \%$ \\
\hline & & Mean & $\mathrm{SD}$ \\
\hline Time Spent Sleeping (minu & & 424.8 & 130.6 \\
\hline Time Spent Doing Homewc & inutes/day) & 94.25 & 70.42 \\
\hline Average Daily MVPA (minu & & 122.11 & 81.31 \\
\hline
\end{tabular}

Table 2 - Relationship between Physical Activity Predictors and English Grades: Ontario and Alberta, 20132014/2015-2016 


\begin{tabular}{|c|c|c|c|c|c|c|c|c|c|c|c|c|}
\hline & \multicolumn{3}{|c|}{ Model 1} & \multicolumn{3}{|c|}{ Model 2- MVPA } & \multicolumn{3}{|c|}{$\begin{array}{c}\text { Model 3- Meets } \\
\text { Guidelines }\end{array}$} & \multicolumn{3}{|c|}{$\begin{array}{c}\text { Model 4- Sports } \\
\text { Participation }\end{array}$} \\
\hline & Est. & S.E. & $\begin{array}{c}\mathrm{p}- \\
\text { value }\end{array}$ & Est. & S.E. & $\begin{array}{c}\mathrm{p}- \\
\text { value }\end{array}$ & Est. & S.E. & p-value & Est. & S.E. & p-value \\
\hline \multicolumn{13}{|l|}{ Intercept } \\
\hline & 2.87 & 0.07 & $<.00$ & 2.90 & 0.07 & $<.00$ & 2.89 & 0.07 & $<.00$ & 2.85 & 0.07 & $<.00$ \\
\hline \multicolumn{13}{|l|}{ Grade } \\
\hline \multicolumn{13}{|l|}{9 (ref) } \\
\hline 10 & 0.09 & 0.02 & $<.00$ & 0.09 & 0.02 & $<.00$ & 0.09 & 0.02 & $<.00$ & 0.09 & 0.02 & $<.00$ \\
\hline 11 & 0.15 & 0.05 & 0.00 & 0.15 & 0.05 & 0.00 & 0.15 & 0.05 & 0.00 & 0.15 & 0.05 & 0.00 \\
\hline 12 & 0.22 & 0.62 & 0.72 & 0.22 & 0.62 & 0.72 & 0.22 & 0.62 & 0.72 & 0.22 & 0.62 & 0.72 \\
\hline \multicolumn{13}{|l|}{ Sex } \\
\hline \multicolumn{13}{|l|}{ Female (ref) } \\
\hline Male & -0.25 & 0.02 & $<.00$ & -0.24 & 0.02 & $<.00$ & -0.24 & 0.02 & $<.00$ & -0.25 & 0.02 & $<.00$ \\
\hline \multicolumn{13}{|l|}{ Ethnicity } \\
\hline \multicolumn{13}{|l|}{ White (ref) } \\
\hline Asian & -0.03 & 0.04 & 0.52 & -0.03 & 0.04 & 0.46 & -0.03 & 0.04 & 0.46 & -0.02 & 0.04 & 0.64 \\
\hline Other & -0.15 & 0.03 & $<.00$ & -0.15 & 0.03 & $<.00$ & -0.16 & 0.03 & $<.00$ & -0.15 & 0.03 & $<.00$ \\
\hline Mixed & -0.07 & 0.04 & 0.04 & -0.07 & 0.03 & 0.04 & -0.07 & 0.03 & 0.04 & -0.07 & 0.04 & 0.05 \\
\hline \multicolumn{13}{|l|}{ Spending Money } \\
\hline Zero (ref) & & & & & & & & & & & & \\
\hline$\$ 1$ to $\$ 5$ & -0.05 & 0.04 & 0.17 & -0.05 & 0.04 & 0.19 & -0.05 & 0.04 & 0.19 & -0.05 & 0.04 & 0.16 \\
\hline$\$ 6$ to $\$ 10$ & -0.03 & 0.03 & 0.29 & -0.03 & 0.03 & 0.34 & -0.03 & 0.03 & 0.34 & -0.04 & 0.03 & 0.27 \\
\hline$\$ 11$ to $\$ 20$ & -0.01 & 0.03 & 0.72 & -0.01 & 0.03 & 0.83 & -0.01 & 0.03 & 0.84 & -0.02 & 0.03 & 0.56 \\
\hline$\$ 21$ to $\$ 40$ & 0.00 & 0.03 & 0.88 & 0.00 & 0.03 & 0.97 & 0.00 & 0.03 & 0.98 & -0.01 & 0.03 & 0.66 \\
\hline$\$ 41$ to $\$ 100$ & 0.01 & 0.03 & 0.78 & 0.02 & 0.03 & 0.59 & 0.02 & 0.03 & 0.60 & 0.00 & 0.03 & 0.93 \\
\hline More than $\$ 100$ & -0.04 & 0.04 & 0.33 & -0.03 & 0.04 & 0.50 & -0.03 & 0.04 & 0.47 & -0.05 & 0.04 & 0.23 \\
\hline I don't know & -0.02 & 0.03 & 0.44 & -0.02 & 0.03 & 0.53 & -0.02 & 0.03 & 0.54 & -0.03 & 0.03 & 0.35 \\
\hline
\end{tabular}


Strongly Agree

(ref)

Agree

$\begin{array}{llllllllllll}-0.25 & 0.02 & <.00 & -0.25 & 0.02 & <.00 & -0.25 & 0.02 & <.00 & -0.24 & 0.02 & <.00\end{array}$

Disagree/

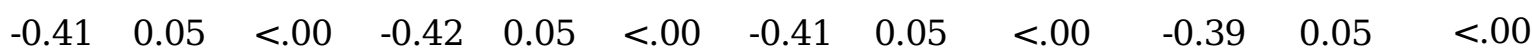

Strongly

Disagree

Grade at Baseline

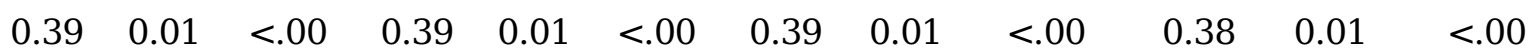

Time Spent Sleeping (minutes/day)

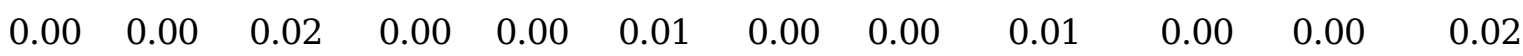

Time Spent Doing Homework (minutes/day)

$$
\begin{array}{llllllllllll}
0.00 & 0.00 & 0.08 & 0.00 & 0.00 & 0.06 & 0.00 & 0.00 & 0.06 & 0.00 & 0.00 & 0.11
\end{array}
$$

Average Daily MVPA (minutes) at Baseline

$$
\begin{array}{lll}
-0.00 & 0.00 & 0.03
\end{array}
$$

Meets PA Guidelines at Baseline

No (ref)

Yes $\begin{array}{lll}-0.05 & 0.02 & 0.00\end{array}$

Intramural Sports Participation

No

Yes

$$
\begin{array}{lll}
0.05 & 0.02 & 0.02
\end{array}
$$

Varsity Sports Participation

No

Yes

League Sports Participation

No

Yes

Estimates generated using linear regression mixed models. 
Table 3 - Relationship between Physical Activity Predictors and Math Grades: Ontario and Alberta, 2013$2014 / 2015-2016$ 


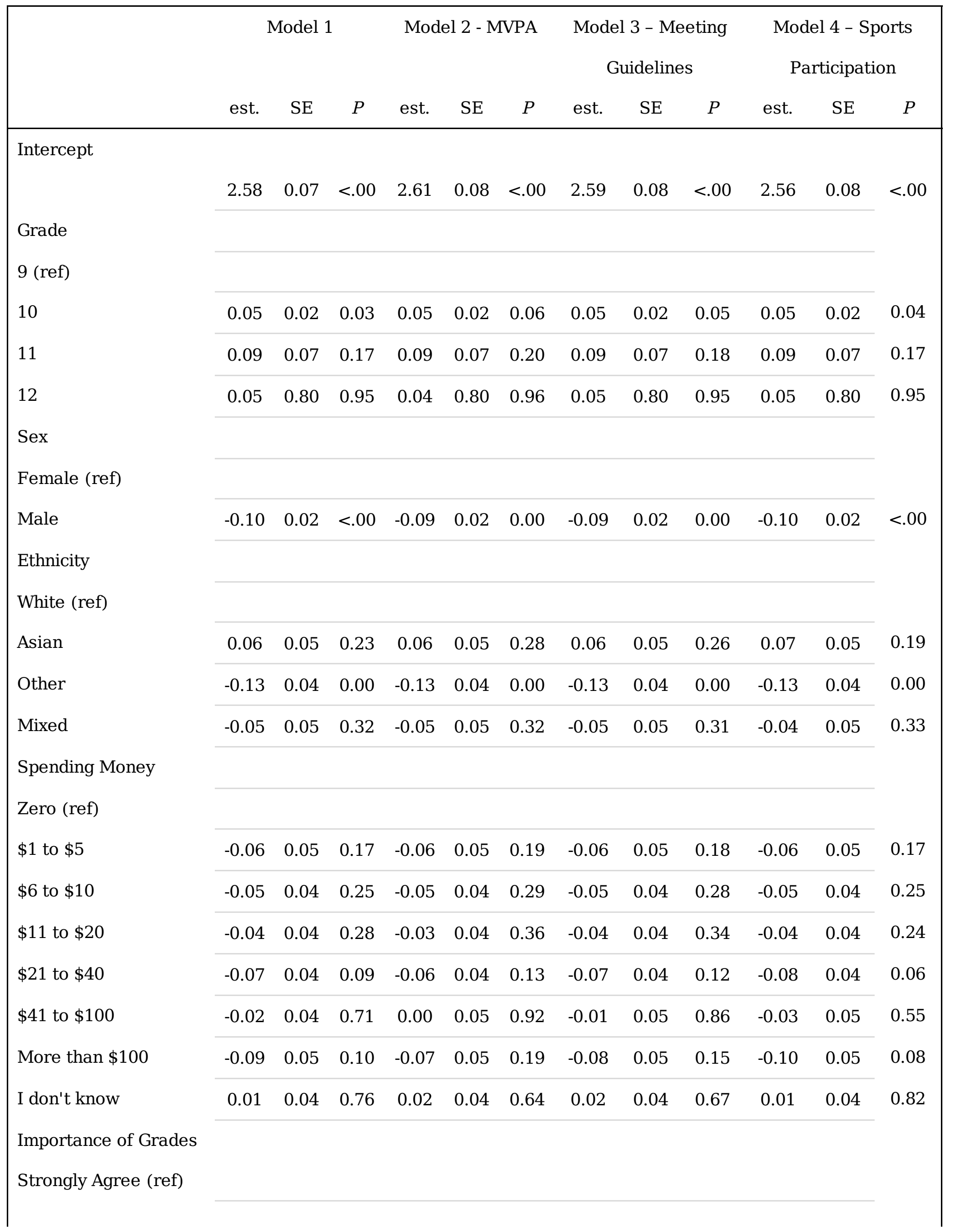




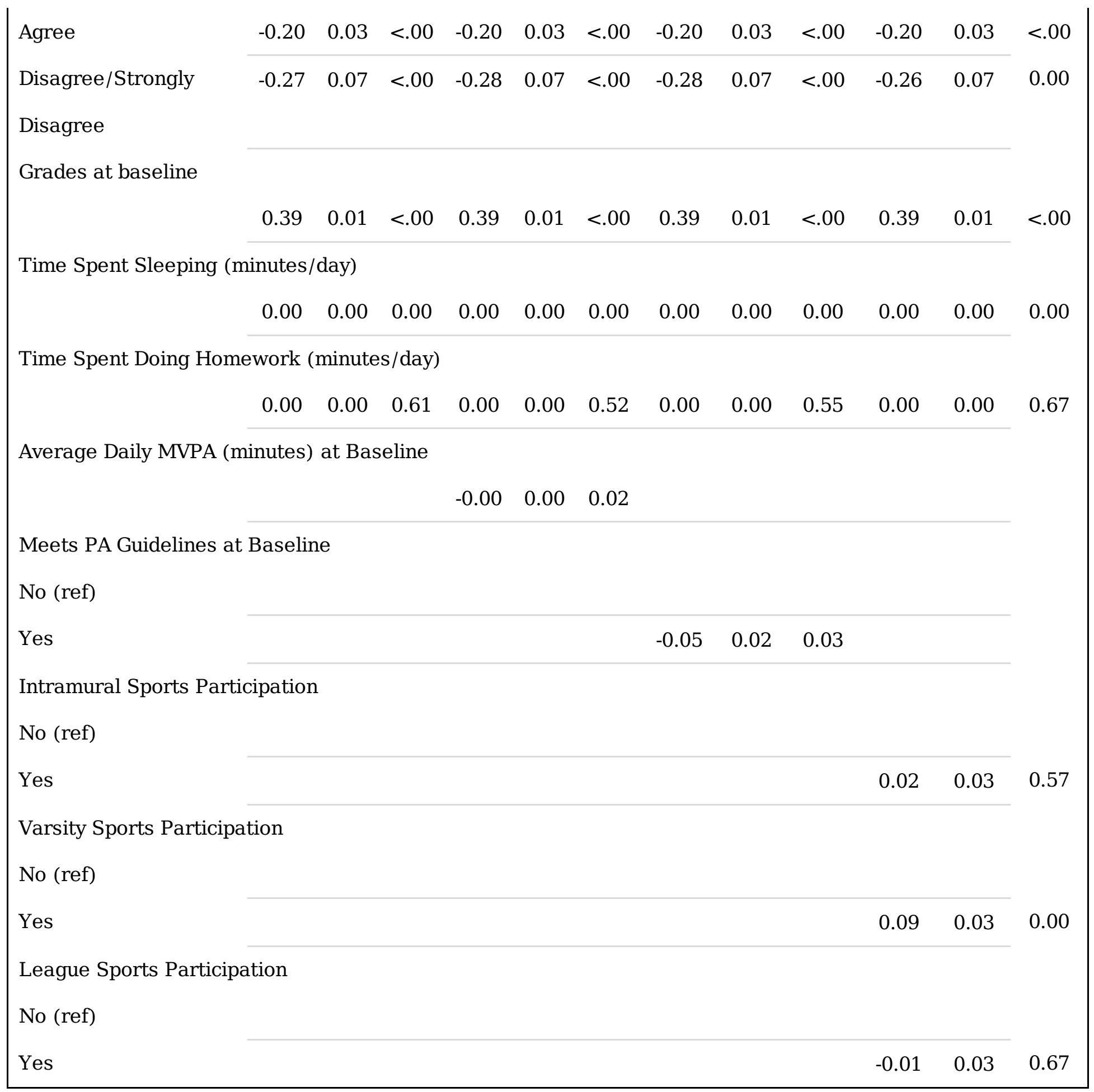

Estimates generated using linear regression mixed models.

Table 4 - Cohen's f Effect Sizes for the Relationship Between Physical Activity Predictors and Academic Outcomes: Ontario and Alberta, 2013-2014/2015-2016 


\begin{tabular}{|lcc|}
\hline & English Grade & Math Grade \\
\hline Average Daily MVPA (minutes) at Baseline & -0.022 & -0.022 \\
Meets PA Guidelines at Baseline & -0.030 & -0.022 \\
Intramural Sports Participation & 0.028 & 0.017 \\
Varsity Sports Participation & 0.025 & 0.039 \\
League Sports Participation & 0.010 & - \\
\hline
\end{tabular}

Cohen's f values are based on un-clustered data.

Table 5 - Categorical Analysis of the Physical Activity Predictors and Academic Outcomes: Ontario and Alberta, $2013-2014 / 2015-2016$ 


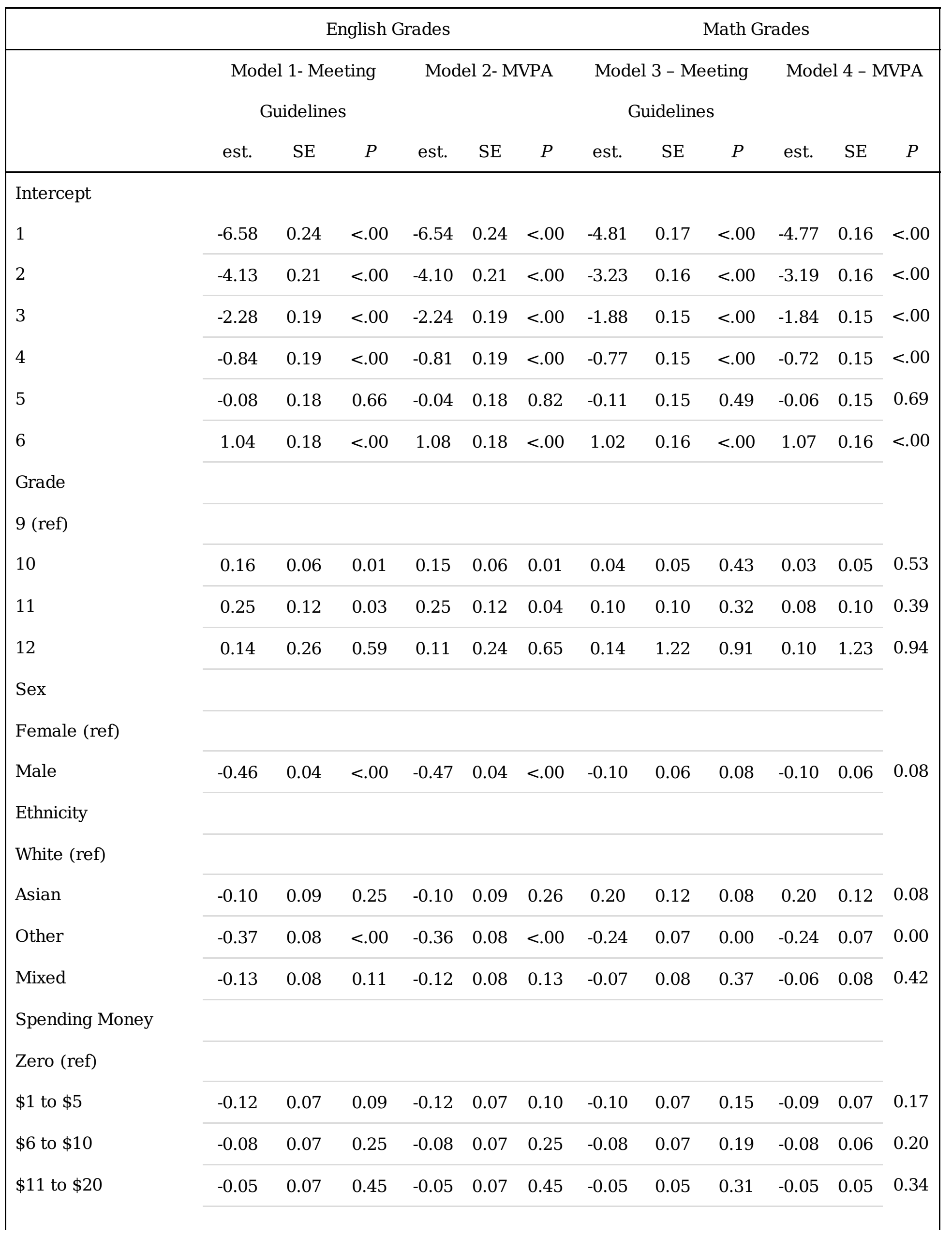




\begin{tabular}{|c|c|c|c|c|c|c|c|c|c|c|c|c|}
\hline$\$ 21$ to $\$ 40$ & -0.05 & 0.07 & 0.49 & -0.04 & 0.07 & 0.54 & -0.11 & 0.06 & 0.06 & -0.11 & 0.06 & 0.08 \\
\hline$\$ 41$ to $\$ 100$ & -0.07 & 0.07 & 0.30 & -0.07 & 0.07 & 0.34 & -0.06 & 0.07 & 0.35 & -0.05 & 0.07 & 0.45 \\
\hline More than $\$ 100$ & -0.16 & 0.10 & 0.09 & -0.15 & 0.10 & 0.13 & -0.16 & 0.09 & 0.08 & -0.13 & 0.09 & 0.13 \\
\hline I don't know & -0.08 & 0.06 & 0.18 & -0.08 & 0.06 & 0.20 & 0.04 & 0.06 & 0.49 & 0.04 & 0.06 & 0.46 \\
\hline \multicolumn{13}{|l|}{ Grades at Baseline } \\
\hline & 0.84 & 0.03 & $<.00$ & 0.84 & 0.03 & $<.00$ & 0.58 & 0.03 & $<.00$ & 0.58 & 0.03 & $<.00$ \\
\hline \multicolumn{13}{|l|}{ Average Daily MVPA } \\
\hline & & & & 0.00 & 0.00 & $<.00$ & & & & 0.00 & 0.00 & $<.00$ \\
\hline \multicolumn{13}{|l|}{ No (ref) } \\
\hline Yes & -0.17 & 0.04 & $<.00$ & & & & -0.14 & 0.04 & 0.00 & & & \\
\hline \multicolumn{13}{|c|}{ Importance of Grades } \\
\hline \multicolumn{13}{|l|}{ Strongly Agree (ref) } \\
\hline Agree & -0.51 & 0.04 & $<.00$ & -0.51 & 0.04 & $<.00$ & -0.33 & 0.04 & $<.00$ & -0.33 & 0.04 & $<.00$ \\
\hline $\begin{array}{l}\text { Disagree/Strongly } \\
\text { Disagree }\end{array}$ & \multicolumn{11}{|c|}{ Disagree } & 0.00 \\
\hline \multicolumn{13}{|c|}{ Time Spent Sleeping (minutes/day) } \\
\hline & 0.00 & 0.00 & 0.02 & 0.00 & 0.00 & 0.02 & 0.00 & 0.00 & 0.15 & 0.00 & 0.00 & 0.13 \\
\hline \multicolumn{13}{|c|}{ Time Spent Doing Homework (minutes/day) } \\
\hline & 0.00 & 0.00 & 0.00 & 0.00 & 0.00 & 0.00 & 0.00 & 0.00 & 0.01 & 0.00 & 0.00 & 0.01 \\
\hline \multicolumn{13}{|c|}{ Intramural Sports Participation } \\
\hline \multicolumn{13}{|l|}{ No (ref) } \\
\hline Yes & 0.13 & 0.06 & 0.02 & 0.14 & 0.06 & 0.01 & 0.08 & 0.05 & 0.16 & 0.09 & 0.05 & 0.10 \\
\hline \multicolumn{13}{|c|}{ Varsity Sports Participation } \\
\hline \multicolumn{13}{|l|}{ No (ref) } \\
\hline Yes & 0.14 & 0.05 & 0.01 & 0.15 & 0.05 & 0.01 & 0.20 & 0.04 & $<.00$ & 0.21 & 0.04 & $<.00$ \\
\hline \multicolumn{13}{|c|}{ League Sports Participation } \\
\hline \multicolumn{13}{|c|}{ No (ref) } \\
\hline Yes & 0.03 & 0.05 & 0.55 & 0.05 & 0.05 & 0.32 & 0.00 & 0.05 & 0.92 & 0.02 & 0.05 & 0.67 \\
\hline
\end{tabular}


Estimates generated using multinomial ordinal Generalized Estimating Equations (GEE) models.

Figures

A)

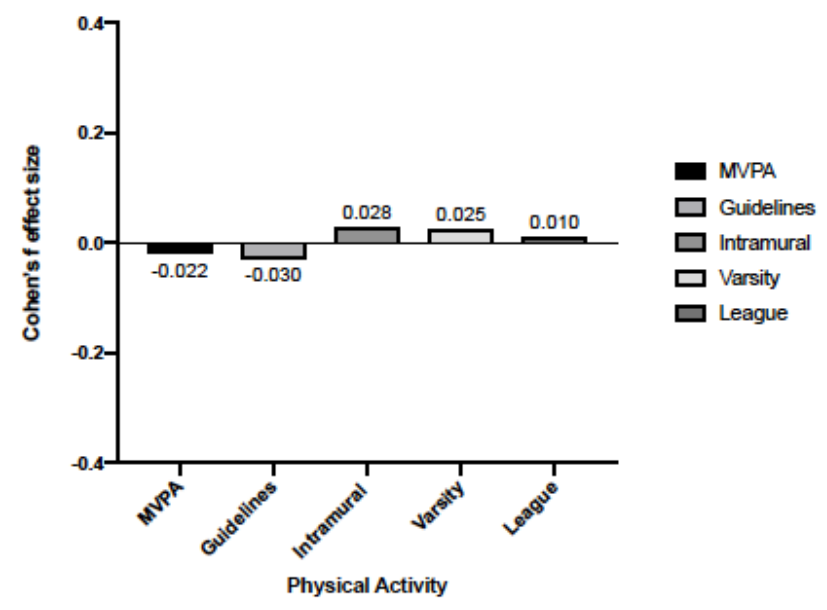

B)

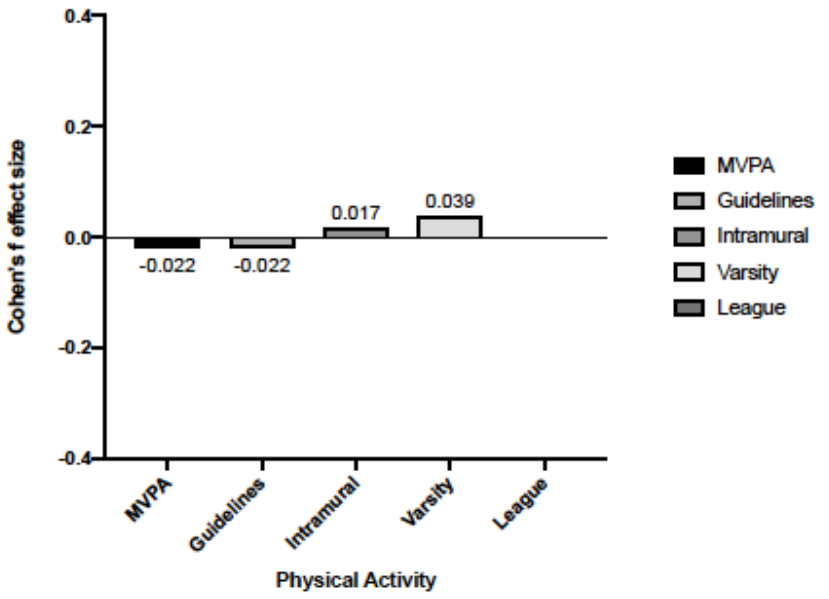

Cohen's $f$ values are based on un-clustered data. 


\section{Figure 1}

Cohen's f Effect Size for the Relationship Between Physical Activity Predictors and a) English Grades as well as b) Math Grades: Ontario and Alberta, 2013-2014/2015-2016 